Heinz Geiger - Albert Klein - Jochen Vogt

Hilfsmittel und Arbeitstechniken der Literaturwissenschaft 
Grundstudium Literaturwissenschaft

Hochschuldidaktische Arbeitsmaterialien

Herausgegeben von

Heinz Geiger, Albert Klein und Jochen Vogt unter Mitarbeit von Bernhard Asmuth, Horst Belke, Luise Berg-Ehlers und Florian Vaßen

Band 2

Westdeutscher Verlag 
Heinz Geiger · Albert Klein · Jochen Vogt

\section{Hilfsmittel und Arbeitstechniken der Literaturwissenschaft}

2., neubearbeitete Auflage

Westdeutscher Verlag 
2., neubearbeitete Auflage 1972

Unveränderter Nachdruck der 2., neubearbeiteten Auflage 1976

(C) 1976 Westdeutscher Verlag GinbH, Opladen

(C) 1971 Verlagsgruppe Bertelsmann GmbH / Bertelsmann Universitätsverlag, Düsseldorf

Umschlaggestaltung: J. Seifert

ISBN 978-3-531-29272-4

ISBN 978-3-322-85718-7 (eBook)

DOI 10.1007/978-3-322-85718-7 
I. Textkritik und Edition als Voraussetzung literaturwissenschaftlicher Arbeit ......................7

1. Warum Textkritik? ................. 7 Textveränderung al's Fehlerquelle - Beispiele für Textverderbnis - Geschichte der Textkritik.

2. Kriterien und Methoden der Edition $\ldots \ldots \ldots \ldots \ldots \ldots 11$ Historisch-kritische Ausgaben - Überlieferungsträger und Siglen - Varianten und textkritischer Apparat - Studienausgaben - Textmodernisierung.

3. Beispiel eines kritischen Textes mit Lesartenapparat .......17 Goethe: Heidenröslein.

4. Beispiel eines Paralleldruckes von zwei Textfassungen $\ldots . .21$ Gryphius: Es ist alles eitell.

5. Ermittlung von historisch-kritischen und Erstausgaben . . . . .23

Literaturhinweise . . . . . . . . . . . . . . . . . . .26

Arbeitsvorschläge .......................27

1. Nachschlagewerke und Einführungen $\ldots \ldots \ldots \ldots \ldots 33$ Allgemeine Nachschlagewerke - Literaturwissenschaftliche Nachschlagewerke - Einfuhrende Monographien - Literaturgeschichten.

2. Ermittlung von Sekundärliteratur $\ldots \ldots \ldots \ldots \ldots .46$ Bücherkunde und Bibliographieren - Abgeschlossene Fachbibliographien - Periodische Fachbibliographien - Allgemeine Bibliographien - Zeitschriften.

3. Dokumentation und Auswertung der Literatur . . . . . . . . 59 Dokumentation: Titelkartei - Literaturbeschaffung: Bibliothek - Auswertung: Materialkartei. 
4. Schriftliche Arbeiten im Studium ..............70 Protokoll - Thesenreferat - „paper” - Referat, Examensarbeit, Dissertation.

5. Abfassung und äußere Form der Arbeit . .........74 Gliederung - Rohmanuskript - Zwölf Regeln für die Abfassung textanalytischer Referate - Reinschrift - Titel und Deckblatt - Inhaltsverzeichnis - Zitate und Fußnoten Literaturverzeichnis.

Abkürzungsverzeichnis . . . . . . . . . . . . . 86

Arbeitsvorschläge................... 88

Sachregister. . . . . . . . . . . . . . . . . . . . 100 